Original Research Article

\title{
Evaluation of anticonvulsant activity of aqueous extract of Adhatoda vasica leaves by MES model in rats
}

\author{
Sumitha A. ${ }^{1}$, Saranya R. ${ }^{2 *}$, Dhanasekaran R. $^{3}$, Geetha M. $^{4}$
}

${ }^{1}$ Department of Pharmacology, ACS Medical College and Hospital, Chennai, Tamil Nadu, India

${ }^{2}$ Department of Pharmacology, Madha Medical College, Chennai, Tamil Nadu, India ${ }^{3}$ Department of Paediatrics, Madras Medical College and Hospital, Chennai, Tamil Nadu, India

${ }^{4}$ Department of Pharmacology, JJM Medical College, Davangere, Karnataka, India

Received: 09 November 2018 Accepted: 01 December 2018

\section{*Correspondence to:}

Dr. Saranya R.,

Email: arum.sumithadr@ gmail.com

Copyright: (c) the author(s), publisher and licensee Medip Academy. This is an openaccess article distributed under the terms of the Creative Commons Attribution NonCommercial License, which permits unrestricted noncommercial use, distribution, and reproduction in any medium, provided the original work is properly cited.

\begin{abstract}
Background: Epilepsy is the commonest neurological condition affecting people of all ages, race and social class. The present study was taken up to evaluate the anticonvulsant effect of aqueous extract of leaves of Adhatoda vasica in rats. To evaluate the effect of aqueous extract of Adhatoda vasica leaves on maximal electroshock model in albino rats and to compare the effect of aqueous extract of Adhatoda vasica leaves with standard dose of Phenytoin on Maximal electro shock model.

Methods: Anticonvulsant activity of aqueous extract of Adhatoda vasica was analysed using MES (Maximal electroshock) model. Phenytoin $(25 \mathrm{mg} / \mathrm{kg}$ ) as standard for Maximal electroshock, and two doses of aqueous extract of Adhatoda vasica $(100 \mathrm{mg} / \mathrm{kg}$ and $200 \mathrm{mg} / \mathrm{kg})$ were used as test drugs. Parameters observed in MES were abolition of hind limb tonic extension (HLTE) and time taken to regain righting reflex.

Results: In MES model, control group showed $0 \%$ protection and standard phenytoin group showed $100 \%$ protection. Aqueous extract of Adhatoda vasica at $100 \mathrm{mg} / \mathrm{kg}$ and $200 \mathrm{mg} / \mathrm{kg}$ showed $33.33 \%$ and $50 \%$ protection from seizures respectively. The mean duration of time to regain righting reflex was significantly reduced in Adhatoda vasica groups when compared to control group ( $\mathrm{p}<0.001)$. When groups $100 \mathrm{mg} / \mathrm{kg}$ and $200 \mathrm{mg} / \mathrm{kg}$ of Adhatoda vasica were compared for mean difference in the duration of time to regain righting reflex, statistically nonsignificant results $(\mathrm{p}>0.05)$ were obtained.

Conclusions: Aqueous extract of leaves of Adhatoda vasica has shown significant anticonvulsant action in MES model.
\end{abstract}

Keywords: Adhatoda vasica, Anticonvulsant, Aqueous extract, MES

\section{INTRODUCTION}

Epilepsy is characterised by uncontrolled excessive neuronal activity of either part or all of the central nervous system. ${ }^{1}$ A person who is predisposed to epilepsy has attacks when basal level of excitability of the nervous system rises above a certain critical threshold. As long as the degree of excitability is held below this threshold, no attack occurs. ${ }^{2}$

The lifetime prevalence of experiencing a single seizure is approximately $10 \%$ but only $30 \%$ of incipient seizures recur and become epilepsy. ${ }^{3}$ Antiepileptic drugs (AEDs) are used to suppress or prevent epileptic seizures. But 30 
to 40 percent of patients, children as well as adults remain resistant to drug treatment. ${ }^{4}$

Compliance with medication is a major problem because of long term therapy and adverse effects of many drugs. ${ }^{5}$ So there is still needing to search for ideal antiepileptic drug. Several plants have shown activity when tested on modern bioassays for detection of anticonvulsant activity and many such plants remain to be scientifically investigated. Adhatoda vasica is a part of Acanthaceae plant family which possesses a wide spectrum of medicinal properties. $^{6}$

Adhatoda vasica is a small, evergreen, sub-herbaceous bush which grows in open plains especially in the lower Himalayas (India), Srilanka, Burma and Malaysia. Leaves of Adhatoda vasica are broad, lanceolate having crenate margin, tapering base with characteristic odour. ${ }^{7}$

The leaves of the plant contain an essential oil and alkaloids like vasicine, N-oxides of vasicine, vasicinone, deoxy vasicine etc. ${ }^{8}$ Thus, an effort has been made in the present study to preliminarily evaluate its anticonvulsant activity using aqueous extract in Maximal electroshock (MES) model in animals.

The objective of this study was to evaluate the effect of aqueous extract of Adhatoda vasica leaves on maximal electroshock model (MES) in albino rats. And to compare the effect of aqueous extract of Adhatoda vasica leaves with standard dose of Phenytoin on Maximal electro shock (MES) model in albino rats

\section{METHODS}

The study was carried out at the Department of Pharmacology, JJM Medical College, Davangere, Karnataka, India, after the approval from Institutional Animal Ethics Committee. The duration of the study was 1 year (August 2014- August 2015).

\section{Experimental animals}

Albino rats (male and female), weighing 150-200gms which were bred in central animal house of J.J.M. Medical College, Davangere, was used for the study.

\section{Chemicals and drugs}

- Aqueous extract of Adhatoda vasica leaves was obtained from Natural remedies company, Bangalore.

- Inj. Phenytoin $-25 \mathrm{mg} / \mathrm{kg}$

- Aqueous extract of Adhatoda vasica $-100 \mathrm{mg} / \mathrm{kg}$

- Aqueous extract of Adhatoda vasica $-200 \mathrm{mg} / \mathrm{kg}$

\section{Inclusion criteria}

- Animals weighing 150-200gm albino rats (both male and female).

- Healthy animals with normal behavior

\section{Exclusion criteria}

- Animals weighing more than 200gms and less than $150 \mathrm{gms}$.

- Pregnant female rats.

- Animals used for any other experimental procedure in the past 1 month.

\section{Maximal Electro shock (MES) Model}

\section{Grouping of animals}

Total 24 albino rats were divided in to 4 groups of 6 animals each with distribution of both male and female rats.

- Group A received distilled water $10 \mathrm{ml} / \mathrm{kg}$ i.p. (intraperitoneally) -as control.

- Group B received Inj. Phenytoin $25 \mathrm{mg} / \mathrm{kg}$ i.p. - as standard.

- Group C received Inj.Aqueous. extract of Adhatoda vasica $-100 \mathrm{mg} / \mathrm{kg}$ i.p.

- Group D received Inj.Aqueous. extract of Adhatoda vasica $-200 \mathrm{mg} / \mathrm{kg}$ i.p.

All the injections were given 30 minutes before the electroshock.

The animals were weighed, and appropriate dose of the drug was injected intraperitoneally to different groups. After an interval of 30 minutes they were subjected to Maximal electroshock (MES) stimulation of current of $150 \mathrm{~mA}, 50 \mathrm{~Hz}$ for 0.2 seconds, through transauricular electrodes moistened with saline to prevent any inadvertent thermal injury to the auricles. This resulted in seizures and various phases of seizures and duration of seizures were recorded.

Parameters observed in maximal electro shock

- Abolition of Hind limb tonic extension (HLTE) was taken as an index for anticonvulsant activity.

- Duration of time to regain righting reflex (from the end of HLTE till the animal could stand on 4 limbs).

\section{Evaluation}

Abolition of hind limb tonic extension was taken as an index for anticonvulsant activity. Time taken to regain righting reflex provided information regarding the recovery time after a seizure attack. An effective anticonvulsant drug abolishes HLTE and also shortens the time to regain righting reflex.

\section{Statistical analysis}

Protection in MES induced seizures were recorded as percentage of protection. Other values expressed as mean and standard deviation. Statistical significance was 
calculated by ANOVA and Post-hoc Tukey's test used for inter group comparison. $\mathrm{P}<0.05$ was taken as significant

\section{RESULTS}

In MES model, control group showed $0 \%$ protection, standard phenytoin group showed $100 \%$ protection,aqueous extract of Adhatoda vasica at 100 $\mathrm{mg} / \mathrm{kg}$ and $200 \mathrm{mg} / \mathrm{kg}$ showed $33.33 \%$ and $50 \%$ protection from seizures as shown in Table 1. Mean duration of time to regain righting reflex was significantly lower in both the test groups when compared to control group as shown in Table 2.

Table 1: Group wise comparison of abolition of HLTE in MES model (percentage of protection).

\begin{tabular}{|ll|}
\hline Drugs given & $\%$ Protection \\
\hline Group A (Distilled water-10ml $/ \mathrm{kg})$. & $0(0 \%)$ \\
\hline Group B (Phenytoin- $25 \mathrm{mg} / \mathrm{Kg})$ & $6(100 \%)$ \\
\hline Group C (Adhatoda vasica-100mg/kg) & $2(33.33 \%)$ \\
\hline Group D (Adhatoda vasica-200mg/kg) & $3(50 \%)$ \\
\hline
\end{tabular}

Table 2: Comparison of groups in the duration of time to regain righting reflex in MES model.

\begin{tabular}{|c|c|c|c|}
\hline Drugs given & Mean & $\begin{array}{l}\text { Standard } \\
\text { deviation }\end{array}$ & ANOVA \\
\hline $\begin{array}{l}\text { Group - A (Distilled } \\
\text { water } 10 \mathrm{ml} / \mathrm{kg} .)\end{array}$ & 131 & 22.56 & \multirow{4}{*}{$\begin{array}{l}\mathrm{F}= \\
44.50, \\
\mathrm{P}<0.001\end{array}$} \\
\hline $\begin{array}{l}\text { Group - B (Phenytoin } \\
25 \mathrm{mg} / \mathrm{kg} \text { ) }\end{array}$ & 0 & 0 & \\
\hline $\begin{array}{l}\text { Group - C (Adhatoda } \\
\text { vasica } 100 \mathrm{mg} / \mathrm{kg})\end{array}$ & 41 & 36.41 & \\
\hline $\begin{array}{l}\text { Group - D (Adhatoda } \\
\text { vasica } 200 \mathrm{mg} / \mathrm{kg})\end{array}$ & 10 & 10.97 & \\
\hline
\end{tabular}

Standard group phenytoin at $25 \mathrm{mg} / \mathrm{kg}$ showed $100 \%$ protection from seizures in animals. So, the mean duration of time to regain righting reflex was 0 . This showed that standard group showed maximum protection from seizures when compared to Adhatoda vasica test groups as shown in Table 2.

Table 3: Tukey's post-hoc multiple comparison test showing mean difference between groups in the duration of time to regain righting reflex in MES model.

\begin{tabular}{|lll|}
\hline \multicolumn{3}{|l|}{ Mean Difference between groups } \\
\hline Groups & $\begin{array}{l}\text { Mean } \\
\text { Difference }\end{array}$ & Significance $(\mathbf{P}<\mathbf{0 . 0 5})$ \\
\hline Group A and C & 90.00 & $\mathrm{P}<0.001$ Significant \\
\hline Group A and D & 122.5 & $\mathrm{P}<0.001$ Significant \\
\hline Group C and D & 32.50 & $\begin{array}{l}\text { P }>0.05, \text { Not } \\
\text { Significant }\end{array}$ \\
\hline
\end{tabular}

Post-hoc tukey's multiple comparison test was done to compare mean difference between groups in the duration of time to regain righting reflex in MES model as shown in Table 3.

The mean duration of time to regain righting reflex was significantly reduced in Adhatoda vasica groups when compared to control group ( $\mathrm{p}<0.001)$ though not comparable to standard phenytoin group as it showed maximal $100 \%$ protection from seizures in rats as shown in Table 3.

When groups $100 \mathrm{mg} / \mathrm{kg}$ and $200 \mathrm{mg} / \mathrm{kg}$ of Adhatoda vasica were compared for mean difference in the duration of time to regain righting reflex, statistically non-significant results ( $\mathrm{p}>0.05)$ were obtained as shown in Table 3.

Bar diagram depicting percentage of animals showing abolition of HLTE (Hind limb tonic extension) was shown in Figure 1. Comparison of mean values of time to regain righting reflex between different groups in MES model was shown in Figure 2.

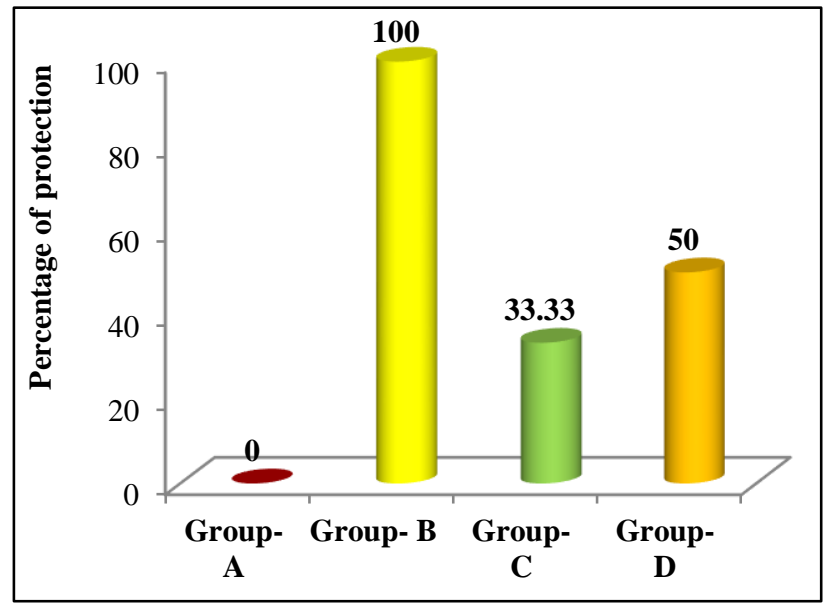

Figure 1: Percentage of animals showing abolition of HLTE in MES model.

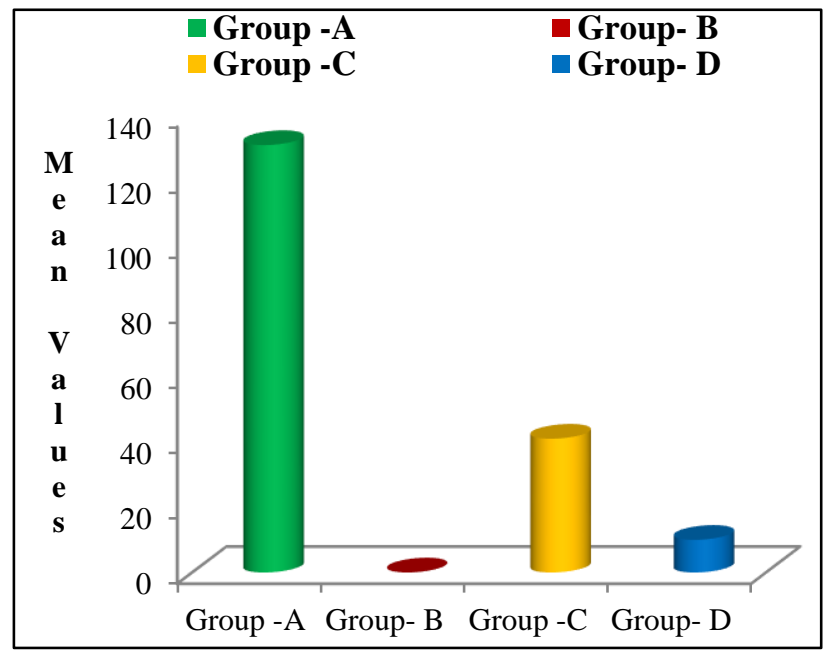

Figure 2: Comparison of mean values of time to regain righting reflex between different groups in MES model. 


\section{DISCUSSION}

Present study was aimed at analysing anticonvulsant activity of aqueous extract of Adhatoda vasica leaves in albino rats and to compare its effect with standard drug. Adhatoda vasica leaves possess a wide spectrum of medicinal properties such as hypoglycemic, antibacterial, antitussive, antiasthmatic, antiulcer, anti-inflammatory property. ${ }^{9}$ MES model- validated experimental method for evaluation of antiepileptic activity of Adhatoda vasica leaves.

In MES model, parameters assessed were presence or absence of hind limb tonic extension (HLTE) and the duration of time to regain righting reflex. In Groups $C$ and D -animals received $100 \mathrm{mg} / \mathrm{kg}$ and $200 \mathrm{mg} / \mathrm{kg}$ of aqueous extract of Adhatoda vasica, the mean duration of time to regain righting reflex was significantly reduced when compared to control group $(\mathrm{p}<0.001)$ as shown in (Table 2 ), but the results were not comparable to standard phenytoin as in this group, $100 \%$ protection was there for animals from seizures.

When groups $\mathrm{C}$ and $\mathrm{D}$ were compared for mean difference in the duration of time to regain righting reflex, statistically non-significant results ( $p>0.05)$ were obtained as shown in (Table 3). Many drugs that are used today in the treatment of epilepsy provide better relief, however their considerable side effects have prompted considerable research in discovering new or related compounds that retain the beneficial action without the adverse effects.

Thus, Adhatoda vasica would be useful alternative as natural products as it tends to have lesser harmful drug reactions when compared to synthetic medications. Similar study conducted previously by Ganga Raju et al, on alcoholic extract of Adhatoda vasica leaves at 100,150 and $200 \mathrm{mg} / \mathrm{kg}$ had shown dose dependant protection from seizures in MES model. ${ }^{7}$

Present study with aqueous extract of Adhatoda vasica has also shown similar results with $100 \mathrm{mg} / \mathrm{kg}$ and $200 \mathrm{mg} / \mathrm{kg}$ in MES model. Preliminary phytochemical studies of aqueous extract of Adhatoda vasica leaves revealed the presence of alkaloids, tannins, saponin, flavonoids, steroids. ${ }^{10}$ The probable active principle responsible for anticonvulsant activity in aqueous extract and the exact mechanism of action are not clearly known and it needs to be confirmed in further studies.

\section{CONCLUSION}

After observing the results of the present study, the following conclusions can be drawn. Aqueous extract of Adhatoda vasica leaves has shown significant anticonvulsant action in Maximal electroshock (MES) model.

\section{ACKNOWLEDGEMENTS}

Authors would like to thank Natural remedies company, Bangalore, for supplying aqueous extract of Adhatoda vasica for the present study.

Funding: No funding sources

Conflict of interest: None declared

Ethical approval: The study was approved by the Institutional Ethics Committee

\section{REFERENCES}

1. Hall JE, editor. Guyton and Hall. $12^{\text {th }}$ ed. Philadelphia: Elsevier; 2011:725-728.

2. Perkin GD. Epilepsy in later childhood and adults. In: Warrell DA, Cox TM, Firth JD. Oxford Textbook of Medicine. $4^{\text {th }}$ ed. New York: Oxford University Press; 2003:1001-1013.

3. Erik K, St Louis, Mark A, Granner. Seizures and Epilepsy in Adolescents and Adults. In: Rakel and Bope,editors. Conn's Current therapy. USA: Elsevier; 2007:1046-1055.

4. Mukhopadhyay HK, Kandar CC, Das SK, Ghosh L, Gupta BK. Epilepsy and its management: a review. J Pharmasci Tech. 2012;1(2):20-6.

5. Schmidt D, Löscher W. Drug resistance in epilepsy: putative neurobiologic and clinical mechanisms. Epilepsia. 2005 Jun;46(6):858-77.

6. Kr PS, Jangra MK, Yadav AK. Herbal and synthetic approaches for the treatment of epilepsy. International J Nutr Pharmacol Neurological Dis. 2014 Jan 1;4(1):43-52.

7. Ganga Raju M, Fernandes J, Vijayanarayana K. Evaluation of antiepileptic activity of the alcoholic extract of Adhatoda Vasica leaves in rats. Res $\mathbf{J}$ Pharmaceut Biol Chem Sci 2011;2(3):5-10.

8. Ahmad S, Garg M, Ali M, Singh M, Athar MT, Ansari SP. A phytopharmacological overview on Adhatoda Zeylanica Medic. syn. A.vasica (Linn)Nees. Natural Product radiance 2009;8(5):549-54.

9. Gangwar AK, Ghosh AK. Medicinal uses and Pharmacological activity of Adhatoda vasica. Int $\mathbf{J}$ Herbal Med. 2014;2(1):88-91.

10. Butler MS. The role of natural product chemistry in drug discovery. J Natural Products. 2004 Dec 28;67(12):2141-53.

Cite this article as: Sumitha A, Saranya R, Dhanasekaran R, Geetha M. Evaluation of anticonvulsant activity of aqueous extract of Adhatoda vasica leaves by MES model in rats. Int $\mathrm{J}$ Basic Clin Pharmacol 2019;8:153-6. 